\title{
The effects of social support and confidence in the health care system on the likelihood of hiring a health advocate
}

This article was published in the following Dove Press journal:

Psychology Research and Behavior Management

17 March 2010

Number of times this article has been viewed

\author{
Terry A Cronan ${ }^{1,2}$ \\ Jordan A Carlson' \\ Jenny Imberi' \\ Miguel Villodas ${ }^{2}$ \\ Elaina Vasserman-Stokes' \\ Ana Dowell' \\ 'Department of Psychology, San \\ Diego State University, San Diego, \\ CA, USA; ${ }^{2}$ Joint Doctoral Program \\ in Clinical Psychology, San Diego State \\ University/University of California, \\ San Diego, CA, USA
}

Background: In response to the increasing complexity of the health care system, the field of health advocacy has emerged. However, little is known about factors that may influence a person's likelihood of hiring a health advocate.

Purpose: This study was designed to examine factors that influence a person's likelihood of hiring a health advocate.

Methods: The participants were 889 randomly selected community members who were assigned to read one of six vignettes. Social support and confidence in the health care system were manipulated in the vignettes. Social support was either high or low and overall confidence was high, moderate, or low. The dependent variables were participants' likelihood of hiring a health advocate and the hourly rate participants were willing to pay for a health advocate for six different services.

Results: The results indicated that social support did not affect the likelihood of hiring a health advocate; however, confidence in the health care system did affect the likelihood of hiring a health advocate. Participants who read vignettes, in which the patient was described as having lower overall confidence levels, indicated a greater likelihood of hiring a health advocate than participants who read the vignettes in which the patient was described as having high confidence.

Conclusions: More research is needed to determine other factors that may influence the likelihood of hiring a health advocate and whether hiring a health advocate is a cost-effective way to improve the quality of health care by reducing the number of medical mistakes and improving patient-provider communication.

Keywords: health advocate, advocacy, social support, confidence, services for hire

Quality and patient satisfaction are primary goals of both health care delivery systems and of the patients seeking care from these systems. Yet the increasing complexity of health care, including rapidly expanding treatment technologies and ever-evolving bureaucracy, has made it difficult to achieve these goals. In today's health care market, it is challenging even for well-informed patients to be certain that their best interests are being met and that they receive the best care possible.

In response to this challenge, the field of health advocacy has been rapidly developing. The field grew out of the patient rights movement of the 1970s. ${ }^{1}$ In 1980, Sarah Lawrence College established the first graduate training program in health advocacy. The Sarah Lawrence program describes health advocates as "patient representatives, ombudsmen, educators, and health advisers helping patients navigate the health care system to ensure that their medical and health needs are met". ${ }^{1}$ Some hospitals
Correspondence: Terry A Cronan Department of Psychology, San Diego State University, 6505 Alvarado Road, Suite II0, San Diego, CA 92120 , USA

Tel +l 6195946915

Fax + I 619594 I247

Email tcronan@sunstroke.sdsu.edu 
have hired patient representatives, a type of health advocate, as regular employees to increase patient satisfaction and improve public relations. Health advocates have been used to provide patients with information about their diagnosis, to provide education and guidance, to see that necessary lab work has been completed, to remind patients to schedule and attend appointments, and to provide emotional support. ${ }^{2,3}$

The American Cancer Society published a report in 1989 that discussed the effects of cancer among low-income people. The authors outlined three major barriers of access to cancer care services, including financial, logistical, and sociocultural. In response to this report, a patient navigation program was implemented in various sites throughout the country to assist low-income people in overcoming these barriers. These programs have not been systematically evaluated, although efforts are underway.

Some investigators have addressed the topic of health advocacy, including defining the various roles of health advocates and discussing the ethical issues involved. ${ }^{4-18}$ In addition to efforts to define health advocacy, researchers have investigated the effects of health advocacy services on medical outcomes. The results indicated that patients using a health advocate receive more recommendations for screening for breast cancer, are more likely to be screened for prostate cancer and receive better care ${ }^{19}$ However, researchers have not examined factors that might influence a person's decision to hire the services of a personal health advocate, or how much people may be willing to pay for these services.

One factor that might affect the likelihood of hiring a health advocate is the patient's level of social support. Research on social support emerged in the late 1970s after Caplan ${ }^{20}$ suggested that social support was related to health. Additional research has supported this relationship, confirming that social support promotes health, protects people against disease, leads to faster recovery, and prevents mortality. $^{21-26}$

Researchers have distinguished between two important aspects of social support, quality and quantity. ${ }^{27}$ Quality of social support was a better predictor of psychological and physical outcomes than was the quantity of social support, among fibromyalgia patients. It has been hypothesized that social support promotes health and protects against social stressors that may have deleterious effects on health. ${ }^{27,28}$ Married people are, on average, physically and mentally healthier, and have lower rates of mortality, than single, widowed or divorced people, ${ }^{26,29-34}$ perhaps because marriage provides people with a sense of meaning and purpose, as well as a means of assistance. It is possible that a health advocate could provide social support to people who are not married, or to those who have little or limited social support available to them. It is also possible that family members who are not able to provide social support, for reasons such as geographical separation or competing demands, may be more likely to hire a health advocate for their loved one. Because increased social support is related to better health, people who lack social support may be more likely to hire a health advocate to provide support. The relationship between social support and the likelihood of hiring a health advocate has not been investigated.

Attitudes and beliefs about the health care system also influence health-related behaviors and use of health services. ${ }^{35}$ People who are confident in the abilities of their hospitals, physicians, and other health care providers are more likely to engage in health-related behaviors and use preventive health services. ${ }^{36-38}$ A person's confidence in the health care system may be influenced by such factors as hospital safety, patient-physician relationships, continuity of care, and overall satisfaction with services. ${ }^{37,39}$ Managed care has been criticized for not adequately meeting patient needs, which leads to declines in patient confidence in the health care system. ${ }^{40-42}$ Health advocates may be able to improve a patient's experience and to increase patient confidence and satisfaction with the health care system through addressing patient needs and personalizing the services received. It is likely that health advocacy services will be more appealing to patients who lack confidence in their current health care providers because they may see a health advocate as someone who can obtain both the needed information and the best services available. Based on both scientific literature and articles in the popular press, confidence in the health care system may be one variable that could influence the likelihood of hiring a health advocate (eg, Reader's Digest, Parade magazines).

Our group considered various potential methodologies to test our hypotheses. In choosing the methodology, we considered two possible choices: conducting qualitative interviews with clinically relevant samples of participants, or distributing vignettes to a randomly selected sample of participants. For several reasons, we chose the vignette approach. First, it avoids problems often associated with standardized interviews by providing a concrete, detailed stimulus and greater control over the survey design, thus increasing internal validity. ${ }^{43}$ The use of vignettes allows us to manipulate the levels of each of the variables of interest more reliably. Second, because our hypotheses were drawn from data based on sampling of the general population, we 
decided that we should confirm them in a similar population before applying them to specialized populations. Because the vignette approach provides a means of collecting objective measures in large sample surveys, we consider it an appropriate methodology for our research question. Finally, the vignette approach is preferable when participants worry about confidentiality.

Social support and confidence were systematically manipulated to examine participants' likelihood of hiring and paying for a personal health advocate. There were two main hypotheses: 1) participants who read vignettes describing a person with low levels of social support would be more likely to hire, and be willing to pay more for, a health advocate than participants who read vignettes describing a person with high levels of social support; and 2) participants who read vignettes in which the person was portrayed as having low confidence in the health care system would be significantly more likely than those who had moderate or high levels of confidence in the health care system to hire, and be willing to pay more for, a health advocate. It was also hypothesized that participants who read the vignettes in which the person described had low levels of social support and low levels of confidence in the health care system would be more likely to hire a health advocate and be willing to pay more for the services than those who read the other combinations of social support and confidence vignettes.

\section{Method}

\section{Sample}

The participants were 889 adults, aged 18 years or older, randomly selected from the community. The mean age of the participants was 50.87 , with $47 \%$ of study participants between the ages of 40 and 64 years; $29 \%$ were aged between 18 and 39 years, and 24\% were aged 65 years or older. Forty-eight percent were male and 79\% were Caucasian. The reported annual family incomes and educational levels are reported in Table 1.

\section{Procedures}

Participants were randomly selected and approached by research assistants in Balboa Park, located in San Diego. Balboa Park is the nation's largest urban cultural park. Situated on 1200 acres, this park is home to 15 major museums, several performance art venues such as the Old Globe Theater, public gardens and the world-famous San Diego Zoo. This park receives more than 500,000 visitors each year from all over the world. Because of San Diego's temperate climate, Balboa Park is host to cultural and entertainment events throughout the year, ranging from free weekly outdoor concerts to astronomy classes and lectures. Inside the park, an outdoor theater and a world-renowned organ pavilion host concerts and plays; there is also a children's puppet theatre and an OMNIMAX theater. Finally, Balboa Park is adjacent to many of

Table I Mean estimated hourly rates for each outcome variable by income levels and expected education level

\begin{tabular}{|c|c|c|c|c|c|c|}
\hline & Stay in hospital & Medical visits & Insurance issues & Medical appts & Health care prof & Treatment options \\
\hline \multicolumn{7}{|l|}{ Income } \\
\hline Less than $\$ 50 \mathrm{k}$ & $\$ 18.1 I^{1}$ & $\$ 17.77^{1}$ & $\$ 20.98^{\prime}$ & $\$ 14.77^{1}$ & $\$ 18.38^{\prime}$ & $\$ 25.56^{\prime}$ \\
\hline $50 \mathrm{k}-\$ 79,999$ & $\$ 23.35^{2}$ & $\$ 22.69^{2}$ & $\$ 26.49^{2}$ & $\$ 17.36^{2}$ & $\$ 21.44^{2}$ & $\$ 32.18^{2}$ \\
\hline More than $\$ 80 \mathrm{k}$ & $\$ 22.85^{2}$ & $\$ 22.85^{2}$ & $\$ 26.73^{2}$ & $\$ 16.58^{2}$ & $\$ 23.34^{2}$ & $\$ 35.16^{2}$ \\
\hline \multicolumn{7}{|l|}{ Expected degree } \\
\hline No education & $\$ 13.36^{1}$ & $\$ 13.781$ & $\mathrm{~N} / \mathrm{A}$ & N/A & N/A & $\mathrm{N} / \mathrm{A}$ \\
\hline HS education & $N / A$ & $\mathrm{~N} / \mathrm{A}$ & $\mathrm{N} / \mathrm{A}$ & $\$ 12.80^{\prime}$ & $N / A$ & $\mathrm{~N} / \mathrm{A}$ \\
\hline Business BA & $\mathrm{N} / \mathrm{A}$ & $N / A$ & $\$ 23.85^{\prime}$ & N/A & N/A & $\mathrm{N} / \mathrm{A}$ \\
\hline Bachelors & $\mathrm{N} / \mathrm{A}$ & $\mathrm{N} / \mathrm{A}$ & $\mathrm{N} / \mathrm{A}$ & $\$ 21.75^{2}$ & N/A & $\mathrm{N} / \mathrm{A}$ \\
\hline LVN & $\$ 18.84$ & $\$ 19.17$ & $\$ 21.38$ & N/A & $\$ 17.92^{1}$ & $\mathrm{~N} / \mathrm{A}$ \\
\hline LCSW & $\$ 20.63$ & $\mathrm{~N} / \mathrm{A}$ & $N / A$ & $\$ 18.03^{2}$ & $\$ 19.02^{\prime}$ & $\mathrm{N} / \mathrm{A}$ \\
\hline RN & $\$ 23.97^{2}$ & $\$ 23.91^{2}$ & $\mathrm{~N} / \mathrm{A}$ & $N / A$ & $\$ 26.88^{2}$ & $\$ 25.70^{\prime}$ \\
\hline Research Master's & $\mathrm{N} / \mathrm{A}$ & $\mathrm{N} / \mathrm{A}$ & $\mathrm{N} / \mathrm{A}$ & N/A & $\mathrm{N} / \mathrm{A}$ & $\$ 30.55$ \\
\hline Research PhD & $\mathrm{N} / \mathrm{A}$ & $\mathrm{N} / \mathrm{A}$ & $N / A$ & $\mathrm{~N} / \mathrm{A}$ & $N / A$ & $\$ 36.02$ \\
\hline Physician & $\$ 36.98^{2}$ & $\$ 31.40^{2}$ & $\mathrm{~N} / \mathrm{A}$ & $N / A$ & $\$ 31.22^{2}$ & $\$ 4 I .5 I^{2}$ \\
\hline Lawyer & $N / A$ & $N / A$ & $\$ 39.24^{2}$ & $N / A$ & N/A & $\mathrm{N} / \mathrm{A}$ \\
\hline
\end{tabular}

Notes: Any mean denoted by a I was significantly lower than any mean denoted by a 2 .

Abbreviations: BA, business analysis; LVN, licensed vocational nurse; HS, high school; N/A, not available; RN, registered nurse. 
San Diego's residential neighborhoods. It was selected as a data collection site primarily because its popularity among visitors allows for the application of random selection procedures. In addition, this park attracts large numbers of culturally diverse participants.

Research assistants approached potential participants and asked them whether or not they would be willing to participate in a study investigating factors associated with decisions made in various health situations. Participants were required to understand and read English to complete the study. Participants were told that their participation would take 5 to 10 minutes and that they would be given US\$5 as a token of appreciation for participation. Interested participants were asked whether they would be able to read two short paragraphs and complete a brief survey. Participants who met the criteria were given a cover letter explaining the purpose of the study, a vignette, and a brief questionnaire to complete. The questionnaires were anonymous and completed individually.

\section{Vignettes}

Participants were randomly assigned to read one of six vignettes that described two levels of social support (low or high) and three levels of confidence in the health care system (low, moderate, or high). The vignettes described a fictitious person, named Scott Barnes, whose physician informed him that he was in need of immediate bypass surgery. He was described as having married his high school sweetheart when he was 24 years old, owning his home, and as having done well with his investments. Scott Barnes' age, gender, and occupation were held constant across all vignettes.

\section{Vignette manipulations Social support}

Social support levels were manipulated by varying the size and cohesiveness of the Barnes family. In the low social support condition, Scott Barnes was said to be a widower whose high school sweetheart passed away when she was 55 years old. He was described as having no children or siblings. His mother passed away 10 years ago. His father was said to have Alzheimer's disease and reside in a nursing home. He was described as being well respected at his engineering firm, but as not socializing outside his work. He was described as having some friends, but since his wife died 5 years ago, having limited contact with them.

In the high social support condition he was described as having a close relationship with his wife and having four children, all of whom were married with children of their own. The Barnes family was described as close knit and as having frequent contact. He was well respected at his engineering firm, and he and his wife often socialized with his associates outside of work. They also had a number of friends with whom they interacted and socialized on a regular basis.

\section{Confidence in the health care system}

Confidence levels were manipulated by changing the quality of care that Scott Barnes believed that he received from his health care providers when he was hospitalized one year before for removal of his gallbladder. In the low confidence condition, he had minimal confidence in his doctors, nurses and other health care providers, was dissatisfied with the care he received, and never felt comfortable asking his physician questions and/or calling him. In the medium confidence condition, he was somewhat confident in his doctors, nurses and other health care providers, was somewhat dissatisfied with the care he received, and had occasionally felt comfortable asking his physician questions and/or calling him. In the high confidence condition Scott Barnes had great confidence in his doctors, nurses and other health care providers, had been extremely satisfied with the care he received, and always felt comfortable asking his physician questions and/or calling him.

\section{Measures}

After reading the vignette, the respondents were asked to assume that they were Scott Barnes and to indicate, using a 10-point Likert-type scale ranging from 1 (extremely unlikely) to 10 (extremely likely), how likely they would be to hire a health advocate. Participants' likelihood of hiring a health advocate was assessed, using six questions that asked how likely they would be to hire a health advocate to: stay with them while in the hospital, accompany them to medical visits, deal with insurance issues, coordinate between health care professionals, research treatment options, and coordinate medical appointments. Respondents were also asked to indicate the highest hourly rate that "Scott Barnes" would be willing to pay a health advocate to perform each of the six services, as well as the highest expected education level appropriate for each service listed.

\section{Demographic characteristics}

The characteristics assessed were age, gender, marital status, level of education, and annual family income. 


\section{Data analysis}

Likelihood of hiring health advocates

Of the six items used to assess Scott Barnes' likelihood of hiring a health advocate, four had significantly skewed distributions and were transformed to correct for nonnormality. They were all strongly correlated with one another $(r$ s ranging from 0.493 to 0.752 ). Although a scale formed using these items yielded an acceptable Cronbach's alpha coefficient of reliability $(\alpha=0.788)$, it was concluded that more detailed information could be obtained by examining the individual variables as outcomes. Thus, all six variables were included as dependent variables (DVs) in a multivariate analysis of variance (MANOVA). However, the sum total score across the six-item scale was used to identify a select sample for follow-up analyses. Zero-order correlations for gender, education, income, marital status, and age with each of the six outcome variables were examined in order to identify potential control variables. Only income, marital status, and age were significantly associated with the outcome and included in the model.

\section{Expected cost of HA services}

Follow-up analyses were conducted in order to assess the amount that participants were willing to pay health advocates for each of the six services used as outcome variables. Individuals who were not very likely to hire a health advocate (ie, those with a sum total scale score on the six outcomes lower than 12 out of 60 ), or who did not respond to how much they would pay a health advocate (eg, missing data), responded that they would pay zero dollars, or whose responses were considered outliers, were excluded from these analyses. Only three observations were considered outliers; they reported that they would pay more than $\$ 700$ per hour for each service. The resulting follow-up sample included 477 people, with whom the follow-up analyses were conducted.

\section{Results}

\section{Likelihood of hiring a health advocate}

A 2 (social support: low or high) by 3 (confidence in the health care system: low, moderate, or high) between-subjects multivariate analysis of variance (MANOVA) was performed on the six DVs while controlling for basic demographic factors including age (3 levels: below 40, 40 to 64, or above 65 ), income ( 3 levels: less than $\$ 50,000$ per year, between $\$ 50,000$ and $\$ 79,999$, or more than $\$ 80,000$ ), and marital status (3 levels: single, married, or divorced/separated/widowed). Although four of the outcome variables were corrected for nonnormality, the means presented for each of these variables have been back-transformed to facilitate meaningful interpretation. Using an alpha level of 0.001 to evaluate homogeneity assumptions, Box's M test of homogeneity of covariance was significant $(P<0.001)$. However, Tabachnick and Fidel ${ }^{44}$ warn of the increased likelihood that this test will indicate heterogeneity of variance as a result of its sensitivity to large sample sizes. Levene's homogeneity of variance test was not statistically significant for any of the six DVs at the $P=0.001$ level, indicating that the assumption of homogeneity of variance was not violated.

In consideration of the number of tests being conducted, a Bonferroni alpha adjustment was used to control the error rates. ${ }^{45}$ Thus, the analyses were conducted using a familywise error rate of $P=0.008$. Using Wilk's criterion $(\Lambda)$ as the omnibus test statistic, the combined dependent variables resulted in a significant main effect, for confidence in the health care system, $F(12,1522)=4.328, P<0.001$, partial $\eta^{2}=0.033$. No main effect was found for social support, and there was no significant interaction between the two variables.

\section{Confidence in the health care system}

To probe the statistically significant multivariate effect for confidence in the health care system, univariate 2 (social support: low or high) by 3 (confidence in the health care system: low, moderate, or high) between-subjects ANOVAs were conducted on each individual dependent variable while controlling for age, income, and marital status. For five of the six outcome variables, there were significant main effects for confidence in the health care system, and post hoc tests were conducted to reveal which means differed significantly (see Table 2 for means). More specifically, for likelihood of hiring a health advocate to stay with you in the hospital, $F(2,766)=16.747, P<0.001$, partial $\eta^{2}=0.042$, the low confidence group $(M=4.92)$ had a significantly higher mean than the moderate $(M=3.99)$ or high $(M=3.36)$ confidence groups. For likelihood of hiring a health advocate to accompany you to your medical visits, $F(2,766)=21.881, P<0.001$, partial $\eta^{2}=0.054$, the low confidence group $(M=4.90)$ had a significantly higher mean than the moderate confidence group $(M=4.03)$, which, in turn, had a significantly higher mean than the high confidence group $(M=3.19)$. For likelihood of hiring a health advocate to deal with insurance issues, $F(2,766)=6.674, P=0.001$, partial $\eta^{2}=0.017$, the low confidence group $(M=6.27)$ had a significantly higher mean than the high confidence group $(M=5.09)$, but the moderate confidence group $(M=5.64)$ did not differ significantly from the low or high confidence groups. 
Table 2 Means for outcome variables by levels of independent variables

\begin{tabular}{lllllll}
\hline & Stay in hospital & Medical visits & Insurance issues & Medical appts & Healthcare prof & Treatment options \\
\hline $\begin{array}{lllll}\text { Social support } \\
\text { Low }\end{array}$ & 4.30 & 4.19 & 5.69 & 3.05 & 4.94 & 4.30 \\
High & 3.84 & 3.85 & 5.65 & 2.63 & 4.70 & 4.26 \\
$\begin{array}{l}\text { Confidence } \\
\text { Low }\end{array}$ & $4.92^{2}$ & & & & \\
Moderate & $3.99^{\prime}$ & $4.90^{3}$ & $6.27^{2}$ & $3.35^{2}$ & $5.48^{2}$ & 4.80 \\
High & $3.36^{\prime}$ & $4.03^{2}$ & 5.64 & $2.70^{\prime}$ & $4.75^{\prime}$ & 4.30 \\
\hline
\end{tabular}

Notes: Means indicated by a I were significantly lower than means indicated by a 2 . Means indicated by a 2 were significantly lower than means indicated by a 3 .

For likelihood of hiring a health advocate to coordinate medical appointments, $F(2,766)=7.259, P=0.001$, partial $\eta^{2}=0.019$, the low confidence group $(M=3.35)$ had a significantly higher mean than the moderate $(M=2.70)$ or high confidence $(M=2.51)$ groups. For likelihood of hiring a health advocate to coordinate between health care professionals, $F(2,766)=10.553, P<0.001$, partial $\eta^{2}=0.027$, the low confidence group $(M=5.48)$ had a significantly higher mean than the moderate $(M=4.75)$ or high confidence $(M=4.22)$ groups. Finally, for likelihood of hiring a health advocate to research various treatment options, significant mean differences were not found, $F(2,766)=4.341$, $P=0.013$, partial $\eta^{2}=0.011$.

\section{Expected cost of HA services MANOVA}

A 2 (social support: low or high) by 3 (confidence in the health care system: low, moderate, or high) by 3 (age: below $45,45-64$, or above 65 ) by 3 (income: less than $\$ 50,000$ per year, between $\$ 50,000$ and $\$ 79,999$, or more than $\$ 80,000$ ) by 3 (marital status: single, married, or divorced/separated/ widowed) between-subjects multivariate analysis of variance (MANOVA) was performed on the six DVs. All six of the outcome variables were transformed to correct for nonnormality; the means presented for each of these variables have been back-transformed to facilitate meaningful interpretation. Using an alpha level of 0.001 to evaluate homogeneity assumptions, Box's M test of homogeneity of covariance was significant $(P<0.001$; for information about this test's sensitivity to sample size, see Tabachnick and Fidel). ${ }^{44}$ Levene's homogeneity of variance test was not statistically significant for any of the six DVs at the $P=0.001$ level.

A Bonferroni alpha adjustment was used again to control the error rates of the tests performed, ${ }^{45}$ resulting in a family-wise error rate of $P=0.008$. Using Wilk's criterion $(\Lambda)$ as the omnibus test statistic, the combined dependent variables did not result in significant main effects for either of the experimental manipulation variables, and there was no significant interaction between the two variables. In fact, the only variable that had a significant main effect was income, $F(12,852)=3.059, P<0.001$, partial $\eta^{2}=0.041$.

\section{Income}

To probe the statistically significant multivariate effect for income, univariate 2 (social support: low or high) by 3 (confidence in the health care system: low, moderate, or high) by 3 (age: below 45, 45-64, or above 65) by 3 (income: less than $\$ 50,000$ per year, between $\$ 50,000$ and $\$ 79,999$, or more than $\$ 80,000$ ) by 3 (marital status: single, married, or divorced/separated/widowed) between-subjects ANOVAs were conducted on each individual dependent variable. For each of the six outcome variables, there was a significant main effect for income, and post hoc tests were conducted to reveal which means differed significantly (see Table 2 for means). More specifically, for "How much would you pay a health advocate to stay with you in the hospital?", $F(2,431)=$ 12.830, $P<0.001$, partial $\eta^{2}=0.056$, individuals earning less than $\$ 50,000$ per year $(M=\$ 18.11)$ estimated that they would pay significantly less than individuals earning between $\$ 50,000$ and $\$ 79,999$ per year $(M=\$ 23.35)$ or individuals earning more than $\$ 80,000$ per year $(M=\$ 22.85)$. For “How much would you pay a health advocate to accompany you to your medical visits?", $F(2,431)=13.159, P<0.001$, partial $\eta^{2}=0.056$, individuals earning less than $\$ 50,000$ per year $(M=\$ 17.77)$ estimated that they would pay significantly less than individuals earning between $\$ 50,000$ and $\$ 79,999$ per year $(M=\$ 22.69)$ or individuals earning more than $\$ 80,000$ per year $(M=\$ 22.85)$. For "How much would you pay a health advocate to deal with insurance issues?", $F(2,431)=$ 12.375, $P<0.001$, partial $\eta^{2}=0.054$, individuals earning less than $\$ 50,000$ per year $(M=\$ 20.98)$ estimated that they would pay significantly less than individuals earning between $\$ 50,000$ and $\$ 79,999$ per year $(M=\$ 26.49)$ or individuals earning more than $\$ 80,000$ per year $(M=\$ 26.73)$. 
For "How much would you pay a health advocate to coordinate medical appointments?", $F(2,431)=6.110$, $P=0.002$, partial $\eta^{2}=0.028$, individuals earning less than $\$ 50,000$ per year $(M=\$ 14.77)$ estimated that they would pay significantly less than individuals earning between $\$ 50,000$ and $\$ 79,999$ per year $(M=\$ 17.36)$ or individuals earning more than $\$ 80,000$ per year $(M=\$ 16.58)$. For "How much would you pay a health advocate to coordinate between health care professionals?", $F(2,431)=7.573, P=0.001$, partial $\eta^{2}=0.034$, people earning less than $\$ 50,000$ per year ( $M=\$ 18.38$ ) estimated that they would pay significantly less than people earning between $\$ 50,000$ and $\$ 79,999$ per year $(M=\$ 21.44)$ or people earning more than $\$ 80,000$ per year $(M=\$ 23.34)$. Finally, for "How much would you pay a health advocate to research various treatment options?", significant mean differences were found, $F(2,431)=9.67$, $P<0.001$, partial $\eta^{2}=0.043$. Individuals earning less than $\$ 50,000$ per year $(M=\$ 25.56)$ estimated that they would pay significantly less than people earning between $\$ 50,000$ and $\$ 79,999$ per year $(M=\$ 32.18)$ or people earning more than $\$ 80,000$ per year $(M=\$ 35.16)$.

\section{Expected educational requirements}

For each of the variables that assessed the amounts that participants were willing to pay health advocates, univariate ANOVAs were conducted in order to test whether or not these estimates varied by individuals' expectations of educational requirements. The family-wise error rate of $P=0.008$ was maintained for these analyses. For "How much would you pay a health advocate to stay with you in the hospital?", $F(5,453)=4.889, P<0.001$, partial $\eta^{2}=0.051$, participants estimated that they would pay someone with no specialized education ( $M=\$ 13.36)$ significantly less than a registered nurse $(M=\$ 23.97)$ or a physician $(M=\$ 36.98)$. For "How much would you pay a health advocate to accompany you to your medical visits?", $F(4,460)=11.158, P<0.001$, partial $\eta^{2}=0.088$, participants estimated that they would pay someone with no specialized education $(M=\$ 13.78)$ significantly less than a registered nurse $(M=\$ 23.91)$ or a physician $(M=\$ 31.40)$. For "How much would you pay a health advocate to deal with insurance issues?", $F(3,459)=18.872$, $P<0.001$, partial $\eta^{2}=0.110$, participants estimated that they would pay someone with a bachelor's degree in business $(M=\$ 23.85)$ significantly less than a lawyer $(M=\$ 39.24)$.

For "How much would you pay a health advocate to coordinate medical appointments?", $F(3,461)=18.118$, $P<0.001$, partial $\eta^{2}=0.105$, participants estimated that they would pay a high school graduate $(M=\$ 12.80)$ significantly less than someone with a bachelor's degree $(M=\$ 21.75)$ or a licensed social worker $(M=\$ 18.03)$. For "How much would you pay a health advocate to coordinate between health care professionals?", $F(4,457)=16.492, P<0.001$, partial $\eta^{2}=0.126$, participants estimated that they would pay a licensed social worker $(M=\$ 19.02)$ or a licensed vocational nurse $(M=\$ 17.92)$ significantly less than a registered nurse $(M=\$ 26.88)$ or a physician $(M=\$ 31.22)$. Finally, for "How much would you pay a health advocate to research various treatment options?", $F(4,455)=7.181, P<0.001$, partial $\eta^{2}=0.059$, participants estimated that they would pay a registered nurse ( $M=\$ 25.70)$ significantly less than a physician $(M=\$ 41.51)$.

\section{Discussion}

In the present study we examined the effects of social support and overall confidence in the heath care system on an individual's likelihood of hiring a health care advocate. Our first hypothesis was that participants assigned to the low social support condition would be more likely to hire a health advocate than participants assigned to the high social support condition. Other studies have indicated that social support is related to health and well-being, ${ }^{21-26,46}$ however, the results of the present study did not support these findings. One possible explanation for this is that the amount of social support does not make a difference in the likelihood of hiring a health advocate. It is also possible that people may not see a health advocate as a vehicle to obtain social support, or that the concept of a health advocate is unfamiliar, and participants may not have understood the services that an advocate could provide. It is also possible that other variables, such as selfefficacy, could mask any effects of social support.

Another hypothesis of the present study was that participants assigned to the low confidence condition would be more likely to hire a health advocate than participants assigned to the moderate or high confidence conditions. This hypothesis was generally supported, except in the likelihood of hiring a health advocate to research various treatments options, where no significant differences were found among any of the levels of confidence. Although no significant differences were found among the three confidence conditions for "likelihood of hiring to research various treatment options," the mean rating across all three groups was higher than for some other services. Thus, our findings indicate that people generally do not feel skilled enough to explore treatment options on their own and believe that they could benefit from assistance. More research is needed to determine whether the likelihood of obtaining assistance with researching treatment options is 
a function of doctor-patient interactions, feelings of inability to evaluate options, or other factors.

Participants who read the vignette with moderate confidence levels indicated a greater likelihood of hiring a health care advocate to stay in the hospital with them and to accompany them to medical appointments than people with high confidence. It seems reasonable that people with less confidence would be more likely to hire a health advocate to increase the possibility that they would receive better care and possibly a better prognosis. Our findings also suggest that patients with less confidence in their health care providers will be the most receptive to, the most in need of, and have the greatest potential to benefit from, health advocacy services.

A notable finding of this study is that people are not comfortable dealing with insurance issues. The mean likelihood of hiring a health advocate to assist with insurance issues was higher for this service than for any of the other services. This information is important both for the field of behavioral medicine and for treatment providers. Providers who assist people with insurance issues may increase patient satisfaction and thereby reduce switching between health care plans. Overall, the data indicated that the respondents' expectations about how much to pay health advocates were markedly lower than the actual salaries of health care professionals. For example, the mean amount of money participants were willing to pay a physician for staying with them in the hospital was $\$ 36.98 /$ hour, $\$ 31.40 /$ hour to accompany them to medical visits, and $\$ 41.51 /$ hour to research treatment options. Also, on average, participants were willing to pay a lawyer only \$39.24/hour to assist them with insurance issues. There are several possible explanations for these estimates. It is possible that the participants interpreted the question "What is the highest hourly rate you would pay for this service?" as how much they would like to pay, and not as how much this professional actually gets paid. Since most of the participants $(88 \%)$ in this study did have health insurance, it is possible that they were unaware of the costs of health care providers and their services. Another explanation could be that the question about how much a participant would be willing to pay for the service preceded the question of expected level of education for the health advocate on the questionnaires. Therefore, it is possible that participants' responses to the payment question may not have been congruent with the level of expected educational requirements. Finally, a possible reason that participants' responses to the likelihood to pay items were incongruous with realistic salaries of professionals could be that people did not clearly understand the role of a health advocate, and therefore were not clear about how much to pay for their services. However, our follow-up analyses did reveal that participants were more likely to hire a health advocate and pay more when their incomes were higher or when the health advocate was perceived to have medical expertise (eg, registered nurses or physicians) than were those with lower incomes. Future researchers may want to consider providing salary ranges for different health advocate services.

Although the use of vignette methodology allowed us to manipulate social support and confidence in the health care system experimentally, it is possible that participants whose confidence in the health care system and social support were different from those described in the scenarios could not relate to the depicted situation. Therefore, the participants' responses may not translate into the actions they indicated on the questionnaire. However, the methodology employed did allow us to sample a wide range of participants and to determine the factors that influence the likelihood of hiring a private health care advocate. Another potential limitation of this study is that participants were randomly selected among those who visited a particular location. Although Balboa Park draws about 500,000 visitors/tourist a year, the people recruited for the study constitute convenience sample. Therefore, the results from this study may not be generalizable to the general population. The sample for this study may be more like those who would hire a health care advocate because their median annual income was higher than that of the general population, and the services of a health care advocate are not presently covered by insurance and would constitute an out of pocket expense. Thus, our sample may be biased toward people who would be more likely to hire a health care advocate. To address these limitations, future researchers may want to target broader groups of participants affected by particular health conditions to gain a more complete understanding of factors that affect the likelihood of hiring a health care advocate.

One implication of the present study is that patients who have low confidence in their health care provider report a greater need to have an advocate to ensure quality health care than those with high or moderate confidence. The findings also indicate that a patient's social support does not appear to affect the decision to hire a health care advocate. This is contrary to what might be expected, based on the literature indicating that people with more social support have better health outcomes. It is also possible that health care providers who include health advocates in the decisions for their patients may increase the participation of the patient in medical decisions and increase patient satisfaction. 
Since the inception of the field of health advocacy, various terms have been used to describe the role of a health advocate, including patient advocate, professional advocate, and patient navigator. While there is an increasing interest in health advocacy, a clear consensus on what a health advocate is, or what his or her duties are, has not yet been reached. If health advocates are to be used to assist in health care delivery or to improve health outcomes, it may be necessary to define their duties and roles more clearly. Organizations such as the National Cancer Institute might help create a more broadly acceptable definition.

The number of medical mistakes, the costs of these mistakes, and the impact of the mistakes on the affected patients have received increasing attention in the public media. ${ }^{47-49}$ It is likely that the use of health advocates could reduce medical mistakes. The services of a health advocate are potentially an important and desirable health benefit. However, more research is needed to determine whether people with a health advocate are more likely than people without a health advocate to receive the treatment they need, or whether using a health advocate results in increased satisfaction. In addition, the perceived benefit to the person receiving the services needs to be examined. Do patients believe that they have benefited from a health advocate? We believe that, with time and effort, health advocacy services may become a cost-effective approach to increased quality of care, increased patient satisfaction, decreased medical errors, and strengthened patient-provider communication.

\section{Disclosures}

The authors report no conflicts of interest in this work.

\section{References}

1. Hurst M. Defining the field: Health advocacy. Available from http:// www.slc.edu/health-advocacy/Defining_the_Field.php. Accessed on March 20, 2009.

2. Jandorf L, Guiterrez Y, Lopez J, Christie J, Itzkowitz SH. Use of a patient navigator to increase colorectal cancer screening in an urban neighborhood health clinic. J Urban Health. 2005;82(2):216-224.

3. Psooy BJ, Schreuer D, Borgaonkar J, Caines JS. Patient navigation: improving timeliness in the diagnosis of breast abnormalities. Can Assoc Radiol J. 2004;55(3):145-150.

4. Martin DR, Tipton BK. Patient advocacy in the USA: Key communication role functions. Nurs Health Sci. 2007;9:185-191.

5. Schwartz L. Is there an advocate in the house? The role of health care professionals in patient advocacy. $J$ Med Ethics. 2001;28(1):37-40.

6. Davis C, Baldry E, Milosevic B, Walsh A. Defining the role of the hospital social worker in Australia. Int Soc Work. 2004;47(3):346-358.

7. Cowles LA, Lefcowitz MJ. Interdisciplinary expectations of the medical social worker in the hospital setting: Part 2. Health Soc Work. 1995;20(4):279-286.

8. Morreim HE. By any other name: the many iterations of "patient advocate" in clinical research. IRB. 2004;26(6):1-8.

9. Benner P. Enhancing patient advocacy and social ethics. Am J Crit Care. 2003;12(4):374-375.
10. Welchman J, Griener GG. Patient advocacy and professional organizations: individual and collective responsibilities. Nurs Ethics. 2005;12:296-304.

11. Atkinson JM, MacPerson K. Patients' advocacy: the development of a service at the state hospital, Carstairs, Scotland. J Ment Health. 2001;10(6):589-596.

12. Baffour TD, Jones MA, Contreras LK. Family health advocacy: an empowerment model for pregnancy and parenting African American women in rural communities. Commun Health. 2005;29(3): 221-228.

13. Hedberg B, Cederborg A, Johanson M. Care-planning meetings with stroke survivors: nurses as moderators of the communication. J Nurs Manage. 2007; 15:214-221.

14. Lennox N, Taylor M, Rey-Conde T, Bain C, Boyle FM, Purdie DM Ask for it: development of a health advocacy intervention for adults with intellectual disability and their general practitioners. Health Promot Int. 2004;19:167-175.

15. O'Connor T, Kelly B. Bridging the gap: a study of general nurses' perceptions of patient advocacy in Ireland. Nurs Ethics. 2005; 12:453-467.

16. Rodney M, Clasen C, Goldman G, Markert R, Deane D. Three evaluation methods of a community health advocate program. J Community Health. 1988;23(5):371-381.

17. Shannon GR, Wilber KH, Allen D. Reductions in costly healthcare service utilization: findings from the care advocate program. Am Geriatr Soc. 2006;54:1102-1107.

18. Wilber KH, Allen D, Shannon GR, Alongi S. Partnering managed care and community-based services for frail elders: the care advocate program. Am Geriatr Soc. 2003;51:807-812.

19. Freeman HP, Muth BJ, Kerner JF. Expanding access to cancer screening and clinical follow-up among the medically underserved. Cancer Pract. 1995;3:19-30.

20. Caplan G. Support systems and community mental health. In: G. Caplan, editor. Support Systems. New York, NY: Basic Books; 1974.

21. Andrews G, Tennant C, Hewson D, Schonell M. The relation of social factors to physical and psychiatric illness. Am J Epidemiol. 1978;108(1):27-35

22. Berkman LF. The role of social relations in health promotion. Psychosom Med. 1995;57:245-254.

23. Berkman LF, Syme SL. Social networks, host resistance, and morality: a nine year follow-up study of Alameda County residents. Am JEpidemiol. 1979;109(2):186-204.

24. House JS, Robbins C, Metzner HL. The association of social relationships and activities with morality: Prospective evidence from the Tecumseh community health study. Am J Epidemiol. 1982;116(1):123-140.

25. Penninx BWJH, Tilburg TV, Deeg DJH, Kriegsman DMW, Boeke AJP, van Eijk JT. Direct and buffer effects of social support and personal coping resources in individuals with arthritis. Soc Sci Med. 1997;44(3): 393-402.

26. Rees WD, Lutkins SG. Morality of bereavement. $\mathrm{Br}$ Med J. 1967;4:13-16.

27. Franks HM, Cronan TA, Oliver K. Social support in women with fibromyalgia: is quality more important than quantity? J Commun Psychol. 2004;32(4):425-438.

28. Cobb S. Social support as a moderator of life stress. Psychosom Med. 1976;38(5):300-314.

29. Gove WR, Hughes M. Possible causes of the apparent sex differences in physical health: An empirical investigation. Am Sociol Rev. 1979;44:126-146.

30. Gove WR. The relationship between sex roles, marital status, and mental illness. Soc Forces. 1972;51(1):34-44.

31. Kobrin FE, Hendershot GE. Do family ties reduce mortality? Evidence from the United States, 1966-1968. J Marriage Fam. 1977;39(4):737-745.

32. Parkes CM. Effects of bereavement on physical and mental health - a study of the medical records of widows. Br Med J. 1964;2:274-279. 
33. Syme SL. Behavioral factors associated with the etiology of physical disease: a social epidemiological approach. Am J Phys Health. 1974;64:1043-1045.

34. Umberson D. Family status and health behaviors: Social control as a dimension of social integration. J Health Soc Behav. 1987;28:306-319.

35. Andersen R, Newman JF. Societal and Individual Determinants of Medical Care Utilization in the United States. Milbank Mem Fund $Q$ Health Soc. 1973;51(1):95-124.

36. Aday L, Awe WC. Health services utilization models. In: Gochmen DS, editor. Handbook of Health Behavior Research I: Personal and Social Determinants. New York, NY: Plenum Press; 1997. P. 153-172.

37. Gilson L. Trust and the development of health care as a social institution. Social Science and Medicine. 2002;56(2003):1453-1468.

38. Roghmann KJ, Hengst A, Zastowny TR. Satisfaction with medical care: its measurement and relation to utilization. Med Care. 1979;17(5):461-479.

39. Ross CK, Steward CA, Sinacore JM. The importance of patient preferences in the measurement of health care satisfaction. Med Care. 1993;31(12):1138-1149.

40. Davies H. Failing public trust in health services: Implications for accountability. J Health Serv Res Policy. 1999;4(4):193-194.

41. Mechanic D. The managed care backlash: Perceptions and rhetoric in health care policy and the potential for health care reform. Millbank $Q$. 2001;79:281-302.
42. Segall M. From cooperation to competition in national health systems - and back: Impact on professional ethics and quality of care. Int J Health Plann Manage. 2000;15:61-79.

43. Alexander CS, Becker H. The use of vignettes in survey research. Public Opin Q. 1978;42:93-104.

44. Tabachnick BG, Fidel LS. Using Multivariate Statistics. Boston, MA: Peterson Publishing; 2007.

45. Weinfurt KP. Multivariate analysis of variance. In: Grimm LG, Yarnold PR, editors. Reading and Understanding Multivariate Statistics. Washington D.C.: American Psychological Association; 1995. P. 245-276.

46. Kaplan BH, Cassel JC, Gore S. Social support and health. Med Care. 1977;5:47-57.

47. Gallin PF. Advice from an insider: How to prevent medical mistakes. 2008. Reader's Digest. Available from: http://www.rd.com/livinghealthy/prevent-medical-errors/article28080.html. Accessed on March 19, 2009.

48. Mishori R. Don't let a hospital make you sick. Available from http:// www.parade.com/health/2009/02/dont-let-hospital-make-you-sick. html. Accessed on March 19, 2009.

49. Winnick LW. Parade. Intelligence report: The most dangerous mistake you can make. 2007. Available from http://www.parade.com/articles/ editions/2007/edition_04-01-2007/Intelligence_Report. Accessed on March 19, 2009.
Psychology Research and Behavior Management

\section{Publish your work in this journal}

Psychology Research and Behavior Management is an international, peerreviewed, open access journal focusing on the science of psychology and its application in behavior management to develop improved outcomes in the clinical, educational, sports and business arenas. Specific topics covered include: Neuroscience, memory \& decision making; Behavior

\section{Dovepress}

modification \& management; Clinical applications; Business \& sports performance management; Social and developmental studies; Animal studies. The manuscript management system is completely online and includes a quick and fair peer-review system. Visit http://www.dovepress. com/testimonials.php to read real quotes from published authors. 